\title{
Road Traffic Injuries among Children-A Tertiary Care Hospital Based Study
}

\author{
Saddar Rahim", Anwar ul Haq1, Shahid Alam, Farooq Abdullah², Ibrar Khan¹. Samiullah.
}

\begin{abstract}
Background: Pakistan is a developing country, its population comprises of more than 200 million people.Approximately more than $1 / 3^{\text {rd }}$ of Pakistan's population is composed of children. Road traffic injuries (RTIs) among children are the leading causes of death and disability and the biggest threat to the health of Pakistani children. This study describes the risk factors involved in causation of RTIs.

Objective: To determine the various risk factors/ predisposing factors involved in causation of road traffic injuries among children. Material and Methods: A cross sectional study of 06 months duration was carried out in a tertiary care hospital. Data was collected from all consecutive victims of RTIs presenting to casualty peadiatric surgery unit Lady Reading Hospital Peshawar and recorded on profoma.

Results: Total 73 victims of RTIs are incuded in the study of whom $68.5 \%(n=50)$ were male. RTIs were common in the age group of $6-12$ years and most of the RTIs, $42.5 \%(n=31)$ occurred between 8 AM to 2 PM. RTls were common in pedestrians, unaccompnied children, families with many children, children from urban areas, and in the month of january. Children of illiterate, poor parents and those children whose parents were laborer were commonly found to be involved in RTIs.

Conclusions: This study has confirmed that the male children of increasing age with poor and illiterate background are the most vulnerable to road traffic injuries. Implementation of road safety meassures, education campaigns, traffic rules and regulations, road engineering and safe pedestrian areas along side the roads will help to reduce road traffic injuries among children.
\end{abstract}

Key Words: road traffic injuries, children, risk factors

This article may be cited as: Rahim S, Haq UA, Alam S, Abdullah F, Khan I, Samiullah. Road Traffic injuries among children- a tertiary care hospital based study. J Saidu Med Coll Swat 2020;10(1):18-21

\section{INTRODUCTION}

Road traffic Injuries have been taking human lives and property worldwide. Road traffic Injuries are the leading cause of death and emergency department visits among US children ${ }^{1}$. Mortality rate due to road traffic injuries among children less than 15 years is five times higher in low and middle income countries as compered to the developed countries $^{2}$. Worldwide, approximately two- thirds of road traffic injury related deaths occur in developing countries. In most countries, road traffic injuries are the leading cause of disability and death among children aged more than 5years ${ }^{3}$. Road traffic Injuries are the second leading cause of disability, the 11th leading cause of premature mortality, and the fifth leading cause of overall healthy years of life lost per 1000 people ${ }^{4}$. RTIs in developing countries contributed to $13 \%$ of total DALYs (disabilityadjusted life years) lost among children in 1990 and the percentage was expected to increase to $22 \%$ by 2020 . Currently RTIs contribute to $3 \%$ of all mortality globally among children aged less

1. Paediatric Surgery/G.Surgery Department, Saidu Group of Teaching Hospital, Swat.

2. Paediatric surgery department, Khyber Teaching, Hospital, Peshawar

Correspondence: Dr Saddar Rahim

HOD-Paediatric surgery Saidu Group of Teaching Hospital Swat

Email address; saddar_raheem77@yahoo.com

Received: October 10th, 2019, Accepted: November 08th, 2019 than 5 years ${ }^{5}$. Children in pre-school age are among the most vulnerable to RTIs ${ }^{6}$

Pakistan is a developing country, its population comprises of more than 200 million people. Approximately more than $1 / 3^{\text {rd }}$ of Pakistan's population is comprised of children ${ }^{7}$. With the increase in growth and age of children their world extends outside their home environment into streets, roads and playgrounds, hence becoming more exposed to the multiple risk factors of injuries. In $21^{\text {st }}$ century injuries are becoming one of the most important public health challenges which are a constant threat to human life. According to research reports almost $1 / 5^{\text {th }}$ of the total global burden of diseases is due to road traffic injuries. Road traffic injuries among children are the leading causes of death and disability and the biggest threat to the health of Pakistani children. Road traffic injuries (RTIs) were likely to be the third most common cause of disability-adjusted life years lost ${ }^{8}$.

Keeping in view the huge burden of road traffic injuries among children in Pakistan, the rational of this study in hand is to help the researchers and health official to focus on this issue in order to prepare effective strategies and policies which could reduce the burden of RTls among child community in Pakistan. The aim of the study is to determine the risk factors leading to RTIs and its prevention. 


\section{MATERIALAND METHODS}

This is a cross-sectional study carried out in a tertiary care hospital from 1st december 2009 to 31st may2010. Consecutive non probability sampling technique was used for collection of data. All the patients upto 12 years of age with road traffic injury were included in this study. Various risk factors such as age, gender, socioeconomic status, education status, residential area and transport of children were studied. Data was collected on prescribed questionaire (preformed proforma) and analyzed by SPSS 16. Informed consent was obtained from parents/ accompanying person of the victims of RTIs for data collection.

\section{RESULTS}

Majority of the victims $52.1 \%(n=38)$ were in the age group of 6-12 years followed by 3-6 years $(28.8 \% \mathrm{n}=21)$. Table 1

Males were the most common victims of RTI. Pie chart $1.28 .8 \%(n=21)$ of RTIs occured in the month of January followed by May and December. Graph 1. $42.5 \%(n=31)$ of accidents were found to occur between $8 \mathrm{am}$ to $8 \mathrm{pm}$. Pie chart 2 Children of urban areas were the most affected $n=52(71.2 \%)$. Majority of children Were found unaccompanied when accident occured. Most of the victims were Pediastriansn $=24(57.5 \%)$ followed by cyclists $=10(13.7)$. This study revealed that $67.1 \%(n=49)$ of the victims were belonging to poor families. The education level of parents was estimated on basis of graduation, Undergratuate/illiterate comprised $60.3 \%(n=44)$. This study also revealed that most of the parents of RTI victims were labourers $61.6 \%(n=45)$ followed by government servants $13.7 \%(n=10)$.

\section{Pie Chart 1. Gender of Victim.}

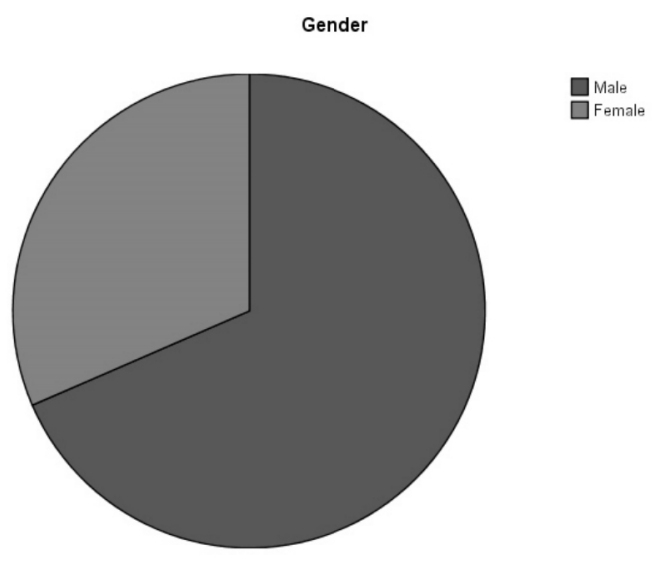

\section{Bar graph 1}

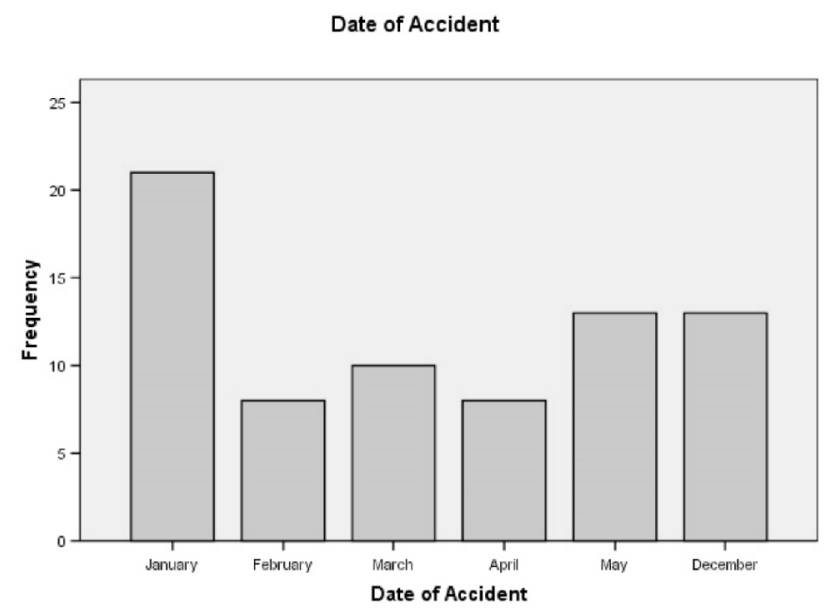

Table 1. Age of the Victim

\begin{tabular}{|c|c|c|c|c|}
\hline Age Group & Frequency & Percent & Valid Percent & $\begin{array}{c}\text { Cumulative } \\
\text { Percent }\end{array}$ \\
\hline $\begin{array}{cc}\text { Valid } & 0-1 \\
& \text { Years } \\
& 1-3 \\
& \text { Years } \\
3-6 \\
\text { Years } \\
6-12 \\
\text { Years } \\
\text { Total }\end{array}$ & $\begin{array}{l}1 \\
13 \\
21 \\
38 \\
73\end{array}$ & $\begin{array}{c}1.4 \\
17.8 \\
28.8 \\
52.1 \\
100.0\end{array}$ & $\begin{array}{c}1.4 \\
17.8 \\
28.8 \\
52.1 \\
100.0\end{array}$ & $\begin{array}{c}1.4 \\
19.2 \\
47.9 \\
100.0\end{array}$ \\
\hline
\end{tabular}




\section{Pie chart 2}

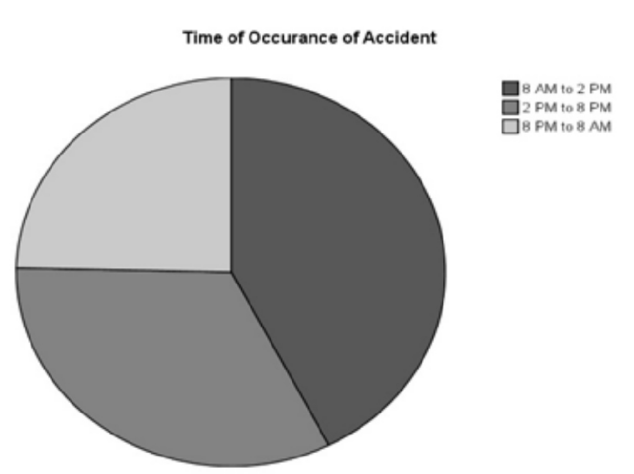

\section{DISCUSSION}

This study has elaborated the different risk factors that were predisposing children to road traffic injuries, presenting to causality pediatric surgery unit Lady Reading Hospital Peshawar. The study included children of age ranging from 0 to 12 years. Findings of this study show that majority of the victims, $(52.1 \%)$ were in the age group of 6-12 years. Increase in the age of children make them more vulnerable to RTIs. The main reason is that at the age of 6 to 12years a child is able to walk, play, run and can cross the road with or with out any accompanying person. The study showed that most of the RTIs occurred when the child was crossing the road or walking along side the road and mismanaged or misunderstood the speed of the vehicle. Increased activities, risk-taking behavior, lack of supervision and shared road spaces are the contributing factors to RTIs in children. Apart from it the driver was unable to manage or understand the movement of the child crossing the road. A study conducted in the city of Karachi by Razzak et al, found that transport injuries were the leading cause of injury among older children aged 514 years. Another study carried out in Sub Saharan Africa show that up to half of the total burden of RTIs is in children under 15 years of age, particularly the 514 years age group $^{7,8}$.

In this study, $68.5 \%$ were the male children, involved in RTIs. This higher incidence of RTIs is because of the male dominant society in which we are living. Boys are more active and can move, walk and go freely outside, while activities of female children are limited to the home environment. According to a study carried out by Krug in 2000, boys are more likely to be involved in RTIs than girls ${ }^{9}$ and the incidence of mortility due to RTIs is 2.5 times higher in males than in females ${ }^{10}$. Bhatti et al, reported most of the road traffic injuries in male children ${ }^{11}$. A study from Nigeria shows that most of the RTIs victims, $72 \%$ were males and the male to female ratio was 2.6:1. A study from South Africa also found the same results, $76 \%$ RTIs victim were male ${ }^{12,13}$.

The current study found that highest number of RTIs, $28.8 \%$ occurred in the month of January. The reason for this increase incidence is the extreme cold and fog in the month of January. $42.5 \%$ RTIs occurred between 8 AM to 2 PM. At this time most of the children go to school and the schools get off at 2PM or some where near to 2PM. And the other reason is that most of the activities of children occur at day time. Least of the RTIs occurred at night as at night the children are limited to home and their outside activities are reduced. The current study also found that $57.5 \%$ were the pedestrians being injured in road traffic accidents. Child riding on bicycle account for $13.7 \%$, as a passenger in motor rickshaws accounts for $8.2 \%$, motor car and minibus $4.1 \%$ in each, riding on motor bike accounts for $6.8 \%$ of RTIs. A study by Hyder AA, in 2006 found that Pedestrians correspond to an average of $68 \%$ of RTIs in children ${ }^{14}$. This high rate of pedestrian injury is also favored by a study carried out by Nantulya VM, in 2003 and according to his study RTIs in developing countries mostly involve pedestrians, cyclists, and passengers. $55-70 \%$ of deaths occurs in pedestrians of urban areas due to road traffic injuries ${ }^{15,16}$. Globally most road traffic injuries occur in developing countries, where urban areas, pedestrians, passengers, and cyclists collectively account for mortality of about $90 \%$ due to road traffic injuries. Research work in Ghana, Kenya, Nigeria, South Africa, and Tanzania has shown that poor children as pedestrians, passengers in buses, and trucks, and cyclists are predominantly susceptible to road traffic injuries ${ }^{17,18}$.

In this study, $69.9 \%$ children were unaccompanied by parents or their relatives during the event of road traffic injuries. This percentage of RTIs in unaccompanied children is favored by the Singer MS, in $2004^{19}$.

The study showed that $69.9 \%$ of the victim's family members were belonging to families having many children and $67.1 \%$ children were belonging to poor families, $60.3 \%$ children parents were undergraduate or illiterate, and $61.6 \%$ victims' parents were laborers. This is favored by a study 
conducted in Pakistan and according to this study Road traffic injuries involve mostly pedestrians, unsupervised children, children from families with many children, children with uneducated mothers are at increased risk of road traffic injuries. Urbanization, increase in motorization rates and failure to institute preventive strategies leads to considerable increase in road traffic deaths in children. Poverty is one of the major risk factors that has an impact on choice of transport, childcare, and access to safety equipments. In most of the urban areas of developing countries, poor children engaging in street hawking or selling goods along the main roads are at increased risk of road traffic injuries.

The other reason which was observed was the implementation of road safety standards. It creates safer environment. Use of child passenger restraints, bicycle helmets and targeted education campaigns are effective preventive measures. Legislation and implementation of traffic rules and regulations, road engineering and Safe pedestrian areas would help reduce injuries as according to Jaung MS, et al (2009) such legislation and implementation of rules can reduce the risk of road traffic injuries up to a greater extent ${ }^{20,21}$.

Pakistan is paying attention on injuries in adults. While children that comprise $43 \%$ of the total population $^{22}$, research work about injuries in this group is still very limited. Lack of information of the basic epidemiology of injuries among children has rendered injury prevention ineffective. In the developing countries like Pakistan relatively little research is conducted on the Road traffic injuries among children as compared to their impact on health and population. There seems to be scarce awareness and this remains a neglected area in research and policies.

\section{CONCLUSION}

It is concluded from our study that children who were prone to road traffic ijuries belong to poor, uneducated families and mostly were unattended living in the urban areas. In addition, our country lack proper legislation of transport, parking, footpath facilities and overall proper public transport system.

\section{REFERENCES}

1. Lee LK, Fleegler EW, Forbes PW, Olson KL, Mooney DP. The modern paediatric injury pyramid: injuries in Massachusetts children and adolescents. Inj Prev 2010; 16(2):123-6.

2. Peden $M$, Oyegbite $K$, Ozanne-Smith J, Hyder AA,
Branche C, Rahman AKMF, et al. World report on child injury prevention. Geneva: World Health Organization;2008.

3. Smith GS, Barss P. Unintentional injuries in developing countries: the epidemiology of a neglected problem. Epidemiol Rev 1991; 13:228-66.

4. Hyder AA, Morrow RH. Applying burden of disease methods in developing countries: a case study from Pakistan. Am J Public Health, 2000; 90 (8):1235-40.

5. Fatmi Z, Kazi A, Hadden WC, Bhutta ZA, Razzak JA, Pappas $G$. Incidence and pattern of unintentional injuries and resulting disability among children under 5 years of age: results of the National Health Survey of Pakistan. Paediatr Perinat Epidemiol 2009;23(3):229-38

6. Majori S, Ricci G, Capretta F, Rocca G Baldovin T,Buonocore F. Epidemiology of domestic injuries. A survey in an emergency department in North-East Italy. J Prev Med Hyg. 2009; 50(3):164-9.

7. Razzak JA, Luby SP, Laflamme L, Chotani H. Injuries among children in Karachi, Pakistan--what, where and how. Public Health. 2004;118(2):114-20.

8. Ruiz-Casares M. Unintentional childhood injuries in subSaharan Africa: an overview of risk and protective factors. J Health Care Poor Underserved. 2009; 20(4 Suppl):5167.

9 Krug EG, Sharma GK, Lozono R. The global burden of injuries. Am J Public Health. 2000; 90(4):523-6.

10. Strukcinskiene B, Uğur-Baysal S, Raistenskis J. Traffic injury mortality trends in children and adolescents in Lithuania among road users. Turk J Pediatr. 2014;56(3):285-90.

11. Bhatti MA, Ajaib MK, Masud TI,Ali M. Road traffic injuries in Pakistan: challenges in estimation through routine hospital data. J Ayub Med CollAbbottabad. 2008; 20(3):108-11.

12. Hyder AA, Muzaffar SS, BachaniAM. Road traffic injuries in urban Africa and Asia: a policy gap in child and adolescent health. Public Health. 2008; 122(10):1104-10.

13. Zwi KJ, Zwi AB, Smettanikov E. Patterns of injury in children and adolescents presenting to a South African township health centre. Inj Prev. 1995; 1(1):26-30

14. Hyder AA, Ghaffar AA, Sugerman DE, Masood TI, Ali L. Health and road transport in Pakistan. Public Health. 2006;120(2):132-41.

15. Nantulya VM, Reich MR. Equity dimensions of road traffic injuries in low and middle-income countries. Inj Control Saf Promot. 2003; 10(12):1320.

16. Brand S, Otte D, Petri M, Decker S, Stübig T, Krettek C, et al. Incidence of posttraumatic stress disorder after traffic accidents in Germany. Int J Emerg Ment Health. 2014;16(1):233-6.

17. Adeoye PO, Kadri DM, Bello JO, Ofoegbu CK, AbdurRahman LO', Adekanye $\mathrm{AO}^{3}$, et al. Host, vehicular and environmental factors responsible for road traffic crashes in a Nigerian city: identifiable issues for road traffic injury control. Pan Afr Med J. 2014 16;19:159.

18. Aladelusi TO, Akinmoladun IV, Olusanya OO, Akadiri OA, Fasola AO. Evaluation of pedestrian road traffic maxillofacial injuries in a Nigerian tertiary hospital. Afr J Med Med Sci. 2014;43(4):353-9.

19. Singer MS. Ghaffar A. Risk factors for road traffic injury in Pakistani children. J Coll Physicians Surg Pak. 2004;14(12): 709-12.

20. Jaung MS, Yu S, Stallones L, Xiang $H$. Road traffic injuries among middle school students in a rural area of China. Traffic Inj Prev. 2009; 10(3):243-51.

21. Gregory B, Irwin JD, Faulks IJ, Chekaluk E. Speeding in school zones: violation or lapse in prospective memory? J Exp Psychol Appl. 2014;20(3):191-8.

22. Qureshi AF, Bose A, Anjum Q. Road traffic injuries: a new agenda for child health. J Coll Physicians Surg Pak. 2004;14(12):719-21. 